\title{
The Murine Ependymoblastoma: Growth Pattern and Survival in C57B1/6J Mice
}

\author{
Paul J. Muller, Kyu H. Shin and Doo H. Shin
}

SUMMARY: The murine ependymoblastoma is a transplantable tumor of cerebral origin. The growth pattern and survival times of the murine ependymoblastoma implanted peripherally and intracranially in non nude C $57 \mathrm{~B} 1 / 6 \mathrm{~J}$ mice have been found to be predictable and consistent when examined by means of Tumor Cell Dose Assessment (end point solution), Tumor Growth and Survival Assessment. The results suggest that a greater tumor cell dose is required to generate peripheral tumor take than brain tumor take. This difference may result from a greater immunologic response to tumor implanted peripherally than into the immunologically privileged brain.

RÉSUMÉ: L'épendymoblastome murin est une tumeur transplantable d'origine cérébrale. Le tableau de croissance et les temps de survie de cet épendymoblastome (lorsqu'implanté en périphérie ou de façon intracrânienne chez la souris C57B1/6J non-nue) furent trouvés constants et prévisibles si examinés par les méthodes d'évaluation de dose cellulaire tumorale, de croissance cellulaire et de survie. Les résultats indiquent qu'il est nécessaire d'employer un plus grand dosage de cellules tumorales pour produire une tumeur périphérique qu'une tumeur cérébrale. Cette différence dépend peut-être de la présence d'une réponse immunologique plus importante à la périphérie.

Can. J. Neurol. Sci. 1983; 10:105-109

Murine brain tumors were originally induced by Seligman and Shear (1939) by the intracerebral implantation of methylcholanthrene. The murine ependymoblastoma was induced and serially transplanted intracerebrally by'Zimmerman and Arnold (1941). This experimental tumor has been used extensively to test the tumoricidal activity of chemotherapeutic agents which might have application in the treatment of human malignant brain tumors (Ausman et al., 1970; Geran et al., 1974; Muller and Tator, 1978; Muller et al., 1980; Shapiro, 1971; Shapiro et al., 1970). The model has also been used in the assessment of radiotherapeutic fractionation (Muller and Shin, 1982), and drug distribution studies (Levin et al., 1970; Schwartz et al., 1972; Tator, 1972; Wassenaar and Tator, 1976).

The mouse ependymoblastoma is relatively easy and inexpensive to maintain by serial transplantation. It grows readily in subcutaneous (s.c.), intramuscular (i.m.) and intracerebral (i.c.) locations; and, it has a remarkably constant growth pattern when implanted i.c. or peripherally. Autochthonous models, in which a tumor is induced by oncoviruses or chemical carcinogens, have long latency periods, a low level of predictability and may require containment. Nitrosourea induced tumors were noted also to have the disadvantage of multiplicity and the occurrence of tumors outside of the central nervous system. The advantages of the autochthonous models include the presence of a natural tumor blood supply and the absence of traumatic tumor implantation (Crafts and Wilson, 1977). Xenographic transplantation into athymic "nude" mice has the disadvantages of long latency, unpredictable tumor take and relative expense. However, the ability to assess human tumor tissue may outweigh these disadvantages (Bullard and Bigner, 1980).
We have examined the growth pattern and the survival times of the murine ependymoblastoma implanted peripherally and i.c. in non nude $\mathrm{C} 57 \mathrm{~B} 1 / 6 \mathrm{~J}$ mice and have found the growth and survival patterns to be predictable and consistent.

\section{MATERIALS AND METHODS Animals}

$\mathrm{C} 57 \mathrm{~B} 1 / 6 \mathrm{~J}$ mice were purchased from the Jackson Laboratories, Bar Harbour, Maine. Generally, 6 - 12 week old female mice weighing $17-21$ grams were used in all experiments. The mice were housed 10 per cage and allowed food and water ad libitam.

\section{Tumor Cell Preparation}

A murine ependymoblastoma was obtained from the laboratory of Dr. C.H. Tator and maintained by serial s.c. transplantation in our laboratory since 1978. Subcutaneous tumors weighing approximately 2 grams were harvested, mechanically disaggregated in phosphate-buffered-saline (PBS), filtered and concentrated by centrifugation (1200 $\mathrm{rpm} \times 10$ minutes). The cell suspensions were then diluted in PBS to yield the desired concentration and cell counts were made with a hemocytometer.

\section{Tumor Inoculation}

Intracerebral tumors were produced by the i.c. injection of $2-6 \mu 1$ of tumor cells suspension with a micrometer syringe via a small stereotactic frame as previously described (Wassenaar et al., 1972). Intramuscular tumors were produced by the direct injection of $100 \mu l$ of tumor cell suspension into the left lower limb thigh musculature. 


\section{Tumor Cell Dose Assessment (End Point Dilution) in I.M. Implanted Tumors}

In each of 10 experiments, 5 serial dilutions of tumor cell suspension were injected into $20 \mathrm{i} . \mathrm{m}$. sites in normal mice (1000 assessible sites in total). The tumor cell concentration varied from $1.6 \times 10^{3}$ to $9.3 \times 10^{6}$ per $100 \mu 1$ ). The mice were observed for the development of tumor for 100 days. The percentage of positive injection sites in each group was plotted against the log of the cell count injected; and the TD50 (the number of tumor cells which produce tumor growth in $50 \%$ of the injection sites) was calculated by least squares regression.

\section{Tumor Growth and Survival Assessment in I.M. Injected Mice}

Twenty-four groups of 10-20 mice were injected with 4.0 to $8.0 \times 10^{6}$ tumor cells into the left thigh musculature. Fourty-eight groups of 10-64 mice (993 mice total) were implanted with $1.3 \times 10^{5}$ to $1.5 \times 10^{6}$ tumor cells intracerebrally. The tumor bearing mice were observed daily for survival and were weighed a minimum of three times weekly. The percent cumulative survival was plotted against time in days after tumor implantation and the median day of death calculated. Mice surviving longer than 100 days after tumor implantation were considered long term survivors and for the sake of further calculations their survival time was considered to be 100 days.

The growth of the i.m. tumors were assessed 3-5 times weekly by measuring the maximum diameter of the tumor bearing leg by ascertaining the best fit through a series of premeasured rings; the diameter was read directly from the ring of best fit. The mean diameter for each experimental group was plotted against time in days after tumor inoculation. The time in days required for the tumor to increase the mean diameter of the leg by $25 \%, 50 \%$ and $100 \%$ was calculated.

In all experiments the day of tumor cell implantation was considered day 1. A different tumor cell suspension was used in each experiment.

\section{RESULTS}

Tumor Growth and Survival Times in I.M. Tumor Bearing Mice

Table 1 summarizes the growth pattern and survival times of $260 \mathrm{i} . \mathrm{m}$. tumor bearing mice in 24 groups. The mean times $( \pm$ S.D.) for a $25 \%, 50 \%$, or $100 \%$ increase in mean leg diameter were $13.1 \pm 3.0,15.3 \pm 3.4$, and $19.9 \pm$ 4.5 days respectively. Figure 1 shows the growth pattern in 13 consecutive groups.

The mean ( \pm S.D.) median day of death MDD was 36.4 \pm 9.7 days. The MDD derived from pooling all the individual survival times of 260 mice was 36 days; the mean survival was $38.1 \pm 15.9$ days. Ninety-two percent of the mice died between the 10th and 60th day after tumor inoculation (Fig. 2.). A single mouse in each of two groups $(0.8 \%)$ died before the mean diameter of the tumor bearing legs of that group exceeded an increase of $25 \%$, in four groups a total of 7 deaths (2.7\%) occurred before the mean diameter increase exceeded $50 \%$, and, in seven groups a total of 10 deaths $(3.8 \%)$ occurred before the mean diameter exceeded $100 \%$.

The linear relationship between MDD and time to increase $25 \%$ was described by $\mathrm{Y}=0.1449 \mathrm{X}+7.8480(\mathrm{r}=$ $0.459, p<0.05$ ). The linear relationship between MDD and time to increase $50 \%$ was best described by $\mathrm{Y}=0.2274 \mathrm{X}$ $+7.0306(r=0.641, p<0.02)$; and, the linear relationship between MDD and time to increase $100 \%$ was best described by $\mathrm{Y}=0.3211 \mathrm{X}+8.1680(\mathrm{r}=0.687$, $\mathrm{p}<0.001)$. The slope of the regression line increased as the end-point diameter enlarged.

\section{Survival Time in I.C. Implanted Mice}

Fig. 3 shows the percent cumulative survival against time in days after the i.c. implantation of $1.3-15.0 \times 10^{5}$ tumor cells into 993 mice in 48 groups of 10 to 64 . Less than $3 \%$ of the mice died prior to the 15 th day after implantation and less than $3 \%$ died after the 60 th day. There were $2.5 \%$ long term survivors. The MDD was 32 days for the whole group and the mean survival was $33.8 \pm 15.0$ days.

\section{Tumor Dose Assessment in I.M. Tumor Bearing Mice}

Table 2 summarizes the tumor cell doses and the percent tumor take in the end point dilution assessment of 10 groups of mice. The mean TD50 ( \pm S.D.) was $1.40( \pm 0.01)$ $\times 10^{5}$.

\section{DISCUSSION}

The murine ependymoblastoma is a stable tumor model derived from cerebral tissue. Our results show that the survival and tumor growth times are predictable and consistent.

The median survival of mice implanted i.c. with $1.3-15.0$ $x 10^{5}$ cells was 32 days and the median survival of mice implanted i.m. with $4.0-8 \times 10^{6}$ cells was 36 days; these survival times are very similar inspite of the larger tumor cell doses used in the i.m. groups. Of course, the mechanism of death was quite different in the two groups. The i.c. implanted mice lost weight terminally and displayed neurologic signs such as somnolence, spinning and movement disruption, whereas the i.m. tumor bearing mice gained weight until death; and, their weight gain paralleled the increase in tumor size. On gross inspection the mechanism of death in the i.m. group appeared to be pelvic invasion of the tumor in a high proportion of the mice.

TABLE 1: The Growth Pattern and Survival Times of Tumor Bearing Mice

\begin{tabular}{c|c|ccc|c}
$\begin{array}{c}\text { Experiment } \\
\text { Numbers }\end{array}$ & $\begin{array}{c}\text { Number } \\
\text { of Mice }\end{array}$ & \multicolumn{3}{|c|}{$\begin{array}{c}\text { Mean Days to Increase } \\
\text { Leg Diameter by }\end{array}$} & $\begin{array}{c}\text { Mean Median } \\
\text { Day Death }\end{array}$ \\
\hline 24 Groups & 260 & $\mathbf{2 5 \%}$ & $\mathbf{5 0 \%}$ & $\mathbf{1 0 0 \%}$ & \\
\hline
\end{tabular}




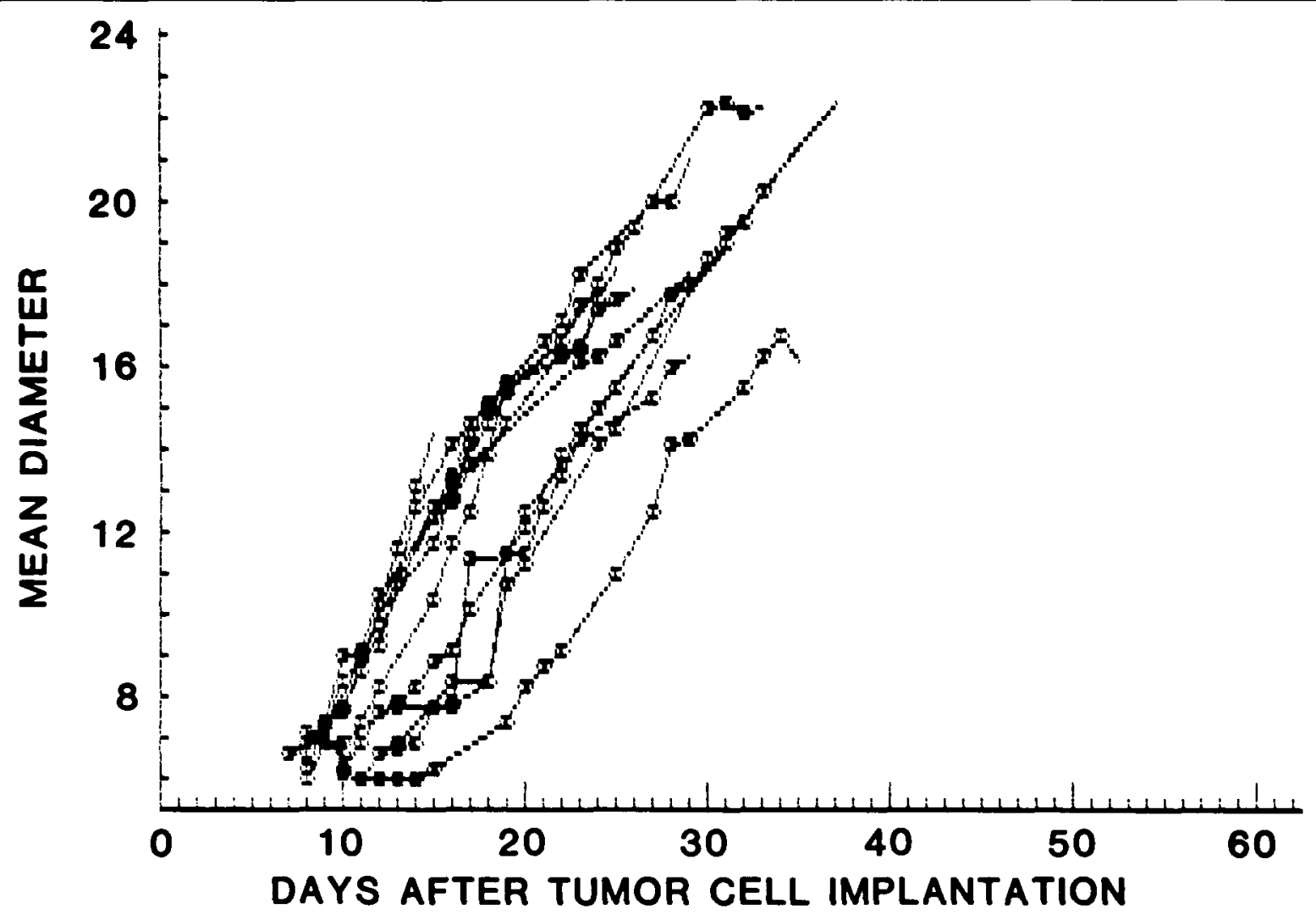

Figure 1 - Mean diameter of tumor bearing limb plotted against days after tumor cell implantation in 13 consecutive experiments.

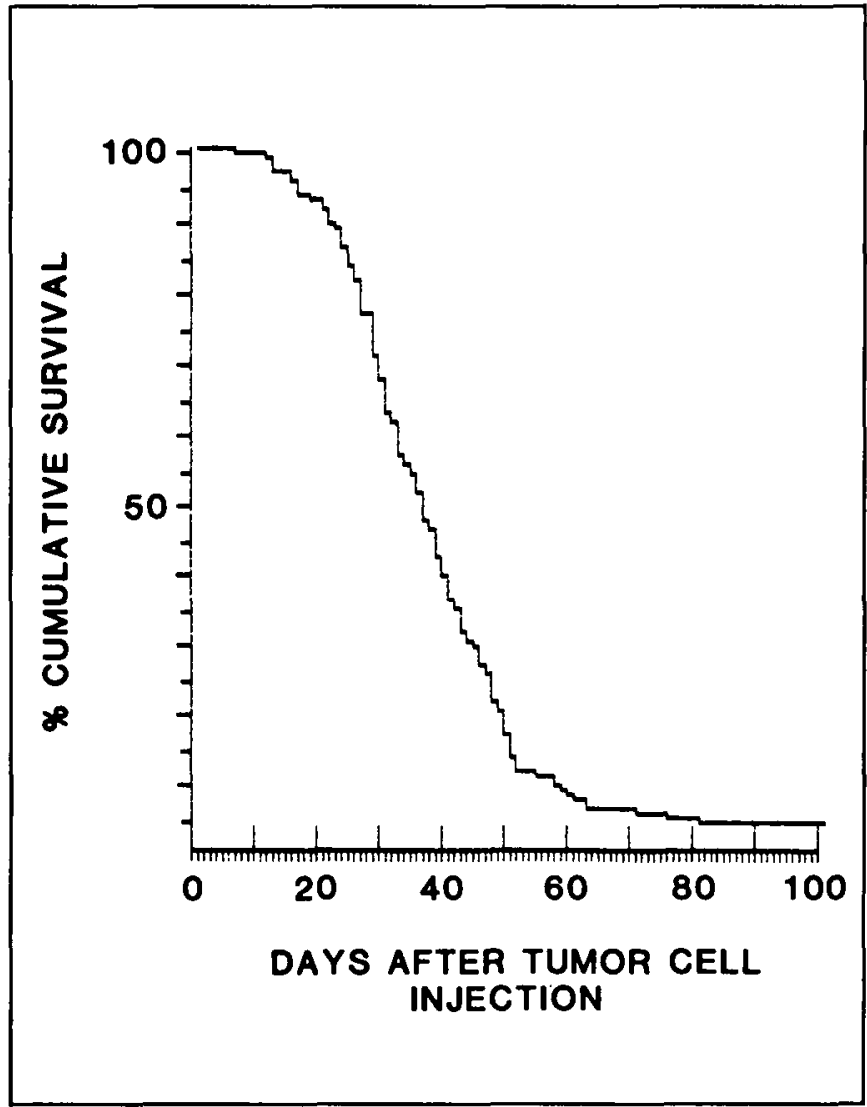

Figure 2 - Percent cumulative survival of intramuscular (leg) bearing mice plotted against time after tumor cell implantation.

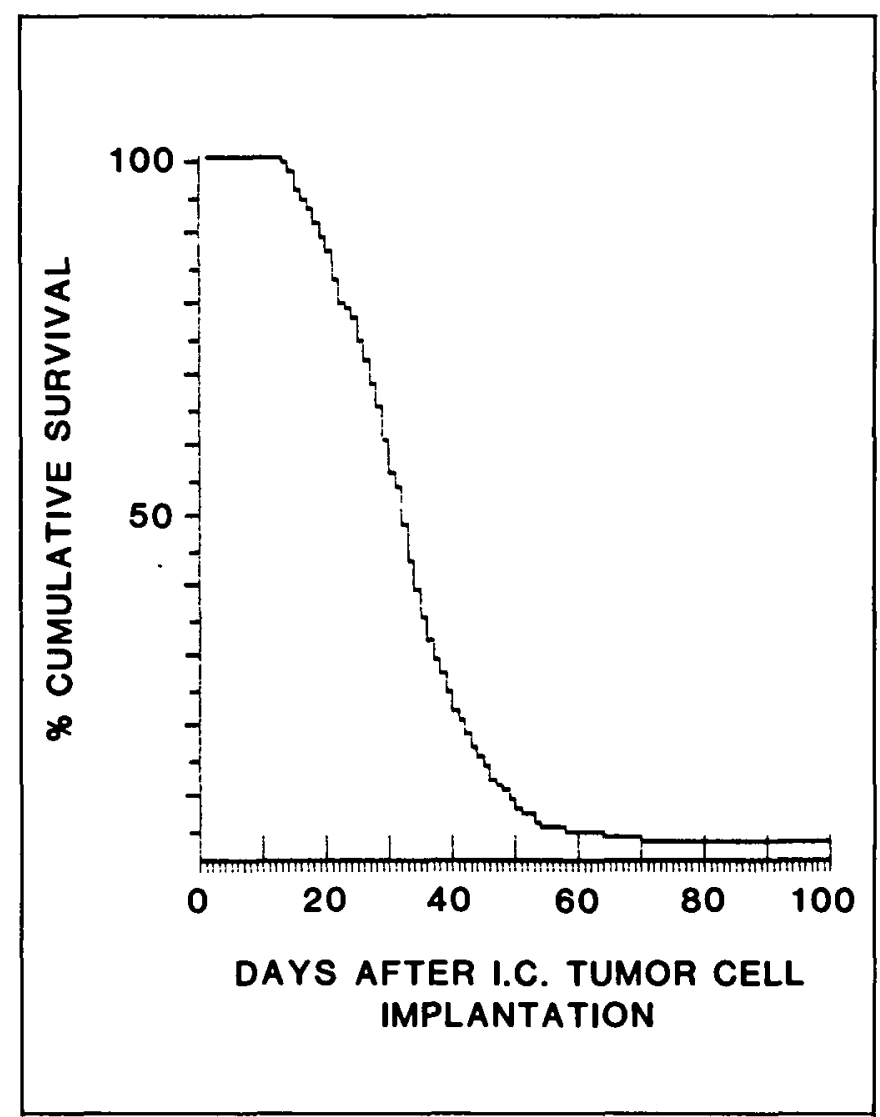

Figure 3 - Percent cumulative survival of intracranial tumor bearing mice plotted against time after tumor cell implantation. 
TABLE 2: Assessment of Rate of Tumor Take After I.M. Implantation

$\begin{array}{cc}\text { Experiment Number } & \text { T.D. 50 x 10s } \\ 1 & 0.63 \\ 2 & 1.00 \\ 3 & 2.47 \\ 4 & 0.794 \\ 5 & 1.58 \\ 6 & 1.41 \\ 7 & 1.58 \\ 8 & 1.00 \\ 9 & 2.24 \\ 10 & 1.26\end{array}$

Five tumor cell doses per experiment

Twenty tumor assessment sites per dose

Tumor Cell Dose Range per $100 \mu 1$ $\left(1.6 \times 10^{3}-9.3 \times 10^{6}\right)$

The TD50 value in the i.m. tumor bearing mice was $1.4 \mathrm{x}$ $10^{5}$ cells; whereas the i.c. tumor bearing mice had virtually a $100 \%$ tumor take at doses over $10^{5}$ tumor cells. Muller and Tator (1977) have shown that $10^{4}$ tumor cells result in a greater than $90 \%$ tumor take when implanted i.c. These results suggest that a greater tumor cell dose is required to generate peripheral tumor take than brain tumor take. A possible explanation of this difference may be a greater immunologic response to tumor implanted peripherally than into the immunologically privileged brain even in syngenetic tumors.

Our data suggests that the i.m. survival times are similar to the survival times for i.c. implanted mice, although an increase in tumor dose may be required. Our results are compatible with those of Suzuki and Tanaka (1980) who used a transplantable Rous virus induced murine glial tumor. They reported a mean survival of 26.2 days after i.c. implantation and 27.8 days after s.c. implantation. The survival times which we observed in the i.c. implanted mice were similar to those reported elsewhere. Ausman et al. (1970) reported a median day of death of 29 days from a sample of 642 mice implanted intracerebrally with a small fragment of tumor tissue; and Wassenaar et al. (1973) reported a MDD of 27.5 in a sample of 200 mice implanted i.c. with tumor cell suspension.

Experimental tumor models have been used extensively to screen potentially useful anti-cancer agents for many years. Experimental tumors of different tissue or species origin may have different responses to the same chemotherapeutic agent. For example, the murine glioma was sensitive to dihydrogalactitol while the rat $9 \mathrm{~L}$ gliosarcoma was much less sensitive (Levin et al, 1970). And, the same experimental tumor may have different sensitivities to the same agent when the tumor is located in an i.c. as opposed to a peripheral location. For example, cyclophosphamide is effective against the L1210 leukemia when the tumor is implanted s.c. but it is not effective when the tumor is implanted i.c. (Chirigos, 1964). Because of the con- sistent growth pattern of the ependymoblastoma when implanted peripherally and because of the relationship between MDD and time for tumor increase, chemotherapeutic agents can be tested in both i.c. and peripheral locations in order to ascertain whether the location of the tumor or its sensitivity influence the effectiveness of the agent.

The murine ependymoblastoma has been used extensively in drug screening trials of the National Cancer Institute (Geran et al, 1974). Generally, the results in this model have been consistent with the findings in human clinical brain tumor trials. The nitrosoureas and procarbazine are effective in prolonging survival in ependymoblastoma bearing mice while mithromycin, cyclophosphamide and methotrexate are ineffective (Shapiro, et al, 1970; Tator et al, 1970). These results parallel the human clinical experience (Walker et al, 1974).

\section{Acknowledgements}

We are indebted to Miss Chris Ledden and Miss Ivy Morgan for technical assistance and to Mrs. Diane Moser and Miss Betty Hendrickson for typing this manuscript.

Our appreciation is extended to Dr. L.M. Jerry, Director, Tom Baker Cancer Centre for his support.

\section{References}

Ausman, J.L., Shapiro, W.R., Rall, D.P. (1970). Studies on the chemotherapy of experimental brain tumors: Development of an experimental model. Cancer Res. 30:2394-2400.

Bullard D.E., Bigner, D.D., (1980). Animal models and virus induction of tumors. In, Brain Tumors. Scientific Basis, Clinical Investigation and Current Therapy. Ed. Thomas, E.D. and Graham, D.I.; Butterworth Inc. pp. 70-76.

Chirigos, M.A., Humphreys, S.R., Goldin, A. (1962). Effectiveness of Cytoxan against intracerebrally and subcutaneously inoculated mouse lymphoid leukemia L1210. Cancer Res. 22:187-195.

Crafts, D., Wilson, C.B. (1977). Animal models of brain tumors. In, Modern Concepts in Brain Tumor Therapy. Laboratory and Clinical Investigations. N.C.I. Monogr. 46, pp. 11-17.

Geran, R., Congleton, G.F., Dudeck, L.E., Vendetti, J., Abbott, B.J., Gargus, J.L. (1974). A mouse ependymoblastoma as an experimental model for screening potential antineoplastic drugs. Cancer Chemothr. Rep. 4:53-87.

Levin, V.A., Shapiro, W.R., Clancy, T.P., Oliverio, V.T. (1970). The uptake distribution, and antitumor activity of 1 - (2-chloroethyl) - 3 -cyclohexyl - 1 nitrosourea in the murine glioma. Cancer Res. 30:2451-2455.

Levin, V.A., Freeman-Dove, M.A., Maroten, C.E. (1970). Dihydrogalactitol (NSC-13213): pharmacokinetics in normal and tumor bearing rat brain and antitumor activity against three intracerebral rodent tumors. J. Natl. Cancer Inst. 56:535.

Muller, P.J., Shin, K.H. (1982). Superfractionated radiotherapy in C57B1/6J mice. Canad. J. Neurol. Sci. 9:295.

Muller, P.J., Tator, C.H. (1978). The effect of amphotericin B on the survival of brain tumor bearing mice treated with CCNU. J. Neurosurg. 49:579-588.

Muller, P.J., Tator, C.H. (1980). Bloom, M. The effect of phenobarbital on the toxicity and tumoricidal activity of CCNU in a murine brain tumor model. $\mathbf{J}$. Neurosurg. 52:359-366.

Schwartz, M.L., Tator, C.H., Hoffman, H.J. (1972). The uptake of hydrocortisone in mouse brain and ependymoblastoma. J. Neurosurg. 36:178-183.

Seligman, A.M., Shear, M.J. (1939). Studies in carcinogenesis. VIII. Experimental production of brain tumors in mice with methylcholanthrene. Am. J. Cancer. $37: 364$.

Shapiro, W.R. (1971). Studies on the chemotherapy of experimental brain tumors. Evaluation of 1 - (2-chlorohexyl) - 3 -cyclohexyl - 1 -nitrosourea, vincristine, and 5 -fluorouracil. J. Natl. Cancer Inst. 46:359-368.

Shapiro, W.R., Ausman, J.I., Rall, D.P. (1970). Studies on the chemotherapy of experimental brain tumors: Evaluation of 1,3 - bis(2 - chloroethyl) - 1 nitrosourea, cyclophosphamide, mithramycin, and methotrexate. Cancer Res. 30:2401-2413. 
Tator, C.H. (1972). Chemotherapy of brain tumors. Uptake of tritiated methotrexate by a transplantable intracerebral ependymoblastoma in mice. J. Neurosurg. 37:1-8.

Walker, M.D. (1977). Brain tumor study group: A survey of current activities. In: Modern Concepts of Brain Tumor Therapy: Laboratory and Clinical Investigations. Natl. Cancer Inst. Mongr. \#46:209-212.
Wassenaar, W., Tator, C.H. (1976). Carbohydrates as potential diagnostic tracers for brain tumors. J. Neurosurg. 44:668-676.

Wassenaar, W., Tator, C.H., So, W.S. (1973). The development of an intracerebral glioma model for brain tumor chemotherapy. J. Neurosurgy. 39:293-301.

Zimmerman, H.M., Arnold, H. (1941). Experimental brain tumors. I. Tumors produced by methylcholanthrene. Cancer Res. 1:919-938. 